Eur. J. Clin. Chem. Clin. Biochem.

Vol. 29, 1991, pp. 737-741

(C) 1991 Walter de Gruyter \& Co.

Berlin - New York

\title{
Aminoterminal Propeptide of Type III Procollagen: A Marker of Disease Activity in Schistosomal Patients
}

\author{
By Véronique Fayol ${ }^{1}$, Hanaa I. Hassanein ${ }^{2}$, Nawal El-Badraw'y ${ }^{2}$, G. Ville ${ }^{1}$ and D. J. Hartmann ${ }^{1}$ \\ 1 Centre de Radioanalyse - CNRS UA 1459 - Institut Pasteur, Lyon, France \\ 2 Theodor Bilharz Research Institute, Imbaba, Guiza, Egypt
}

(Received February 19/August 13, 1991)

\begin{abstract}
Summary: The serum concentration of aminoterminal propeptide of type III procollagen was measured in 44 Egyptian healthy controls and 29 patients with hepatosplenomegaly originating from endemic areas for schistosomiasis in Egypt. Patients were classified into two main groups according to the histopathological pattern of the liver biopsy: patients with active schistosomal liver fibrosis and patients with inactive schistosomal liver fibrosis. Serum aminoterminal propeptide of type III procollagen levels were elevated in most of patients with active fibrosis but not in those with inactive schistosomiasis. From the present work, it is suggested that aminoterminal propeptide of type III procollagen can be used as a marker for active fibrogenesis in patients with schistosomal liver fibrosis.
\end{abstract}

\section{Introduction}

Schistosomiasis, which affects more than 200 million people, is the most prevalent form of hepatic fibrosis worldwide (1). Its pathogenesis is characterized by a cellular immune response (particularly of the delayed type) induced by parasite eggs, which are trapped in the perisinusoidal areas of the host liver, and which cause a granulomatous reaction and a subsequent marked periportal fibrosis $(2,3)$.

Until several years ago, fibrosis was only defined by an excessive deposition of collagen and other components of the extracellular matrix (4). Now, according to Gressner (5), the definition of fibrosis must take into account the complexity of the changes of the liver extracellular matrix $(6-9)$, including an increase, but not all to the same extent, of the contents of most of the extracelluilar matrix molecules, some changes of their microcomposition, and their topographic redistribution. Among the different collagens present in the liver (types I, III, IV, V and VI), types I and III are the most abundant, type III being deposited first, followed by type I during to fibrotic process $(6-11)$.
Since 1979, several attempts have been made to evaluate, in biological fluids, the metabolism of human connective tissue proteins, using radioimmunoassay techniques $(12-13)$. Much has been published on the aminoterminal propeptide of type III procollagen. For serum, the aminoterminal propeptide of type III procollagen levels are increased in various hepatic diseases, and this was interpreted in earlier studies in terms of increased liver collagen synthesis and degradation (14). The relationship between aminoterminal propeptide of type III procollagen and aminotransferase concentrations in serum suggests in fact that the peptide may be released during the active inflammatory phase of the disease by cleavage of tissue III procollagen, thus reflecting inflammation and necrosis and not necessarily fibrosis $(13,15)$.

In schistosomal liver fibrosis, in contrast to other chronic liver diseases, there is a primary hepatic fibrosis with little necrosis. In order to assess the value of aminoterminal propeptide of type III procollagen during evolution of fibrosis, we have measured aminoterminal propeptide of type III procollagen levels 
in schistosomal patients with active and inactive fibrosis. In endemic areas for schistosomiasis and hepatitis, both diseases can be simultaneously present in the same patients, which may result in a more severe form of chronic liver disease. In the present study we therefore retained only patients without associated hepatitis B infection.

\section{Materials and Methods}

Subjects

Healthy subjects (members of the medical and non-medical staff of the Theodor Bilharz Research Institute) were used as controls $(n=44)$; they had no history of schistosomiasis or liver disease.

Patients from endemic areas for schistosomiasis with an hepatosplenic affection were admitted to Theodor Bilharz Research Institute. All subjects were over 17 years old and had normal kidney function as demonstrated by normal creatinine clearance. All patients were subjected to complete clinical examination. They had no evidence of rheumatic diseases. Rectosigmoïdoscopic examinations and stool analysis were performed and showed living or dead Schistosoma mansoni eggs. No Schistosoma haepnatobium eggs were detected in urine.

Liver biopsies were taken from all patients. Liver sections were stained with haematoxylin and eosin, and Masson trichrome. According to the histopathological pattern, only the cases with pure schistosomal liver fibrosis were selected $(n=29)$. In pure schistosomal liver fibrosis, the lobular architecture was preserved with no evidence of necrosis or regeneration; the evidence for schistosomiasis was demonstrated by the presence of eggs, granuloma or pigments. This group was further divided according to the degree of inflammatory cell infiltration and the activity of fibrosis (16): in active liver fibrosis, liver sections showed widening of portal tracts with moderate infiltration of chronic inflammatory cells and fibroblasts $(n=19)$; in inactive liver fibrosis marked thickening of portal tracts, dense fibrosis and minimal cellular infiltration were seen $(n=10)$.

Relevant clinical data are presented in table 1.

Tab. 1. Clinical features of patients with hepatosplenic schistosomiasis

\begin{tabular}{|c|c|c|c|}
\hline \multirow[t]{2}{*}{ Group } & \multirow[t]{2}{*}{ Control } & \multicolumn{2}{|l|}{ Fibrosis } \\
\hline & & active & inactive \\
\hline No. of subjects & 44 & 16 & 13 \\
\hline $\begin{array}{l}\text { Sex } \\
(\delta / \%)\end{array}$ & $29 / 15$ & $14 / 2$ & $11 / 2$ \\
\hline $\begin{array}{l}\text { Age in years } \\
\text { (Range/mean) }\end{array}$ & $24-40 / 29$ & $17-53 / 34$ & $23-53 / 40$ \\
\hline $\begin{array}{l}\text { Liver size } \\
(\mathrm{E} / \mathrm{S})\end{array}$ & normal & $15 / 1$ & $1 / 12$ \\
\hline $\begin{array}{l}\text { Ascites } \\
\text { (yes/no) }\end{array}$ & $0 / 44$ & $0 / 16$ & $2 / 11$ \\
\hline $\begin{array}{l}\text { Varices } \\
\text { (yes/no) }\end{array}$ & $0 / 44$ & $12 / 4$ & $13 / 0$ \\
\hline $\begin{array}{l}\text { S. mansoni eggs } \\
\text { (L/D) }\end{array}$ & $0 / 0$ & $7 / 9$ & $0 / 13$ \\
\hline
\end{tabular}

Liver size is expressed as enlarged (E) or shrunken (S) The eggs were living (L) or dead (D)

\section{Laboratory investigations}

\section{Biochemical determinations}

Liver function tests were performed on sera according to the standard methods using commercial kits (Boehringer Mannheim, Mannheim, Germany). They included: aspartate aminotransferase, alanine aminotransferase, $\gamma$-glutamyl transpeptidase, alkaline phosphatase, total bilirubin.

Electrophoresis was also performéd on sera.

\section{$H B V$ markers}

HBsAg, Anti-HBs, $\mathrm{HBeAg}$, Anti-HBe, Anti-HBc and IgM anti$\mathrm{HBc}$ were assayed by radioimmunoassay (Abbott, Abbott=Park, USA). No patient had positive HBs antigen and/or chronic active hepatitis.

Radioimmunoassay of aminoterminal propeptide of type III procollagen

Bovine $p$ - $N$-III collagen and aminoterminal propeptide of type III procollagen (Col $1-3$ ) extracted from fetal calf skin and rabbit antiserum to purified $p-N$-III collagen (17) were kindly donated by $\operatorname{Dr} B$. Nusgens, Liège (Belgium). Aminoterminal propeptide of type III procollagen was labelled with ${ }^{125}$ I by the chloramine $\mathrm{T}$ method and the radioimmunoassay procedure was modified from Pierard et al. (17) (Hartmann et al., in preparation) as follows. A dilution of an antiserum $(0.1 \mathrm{ml})$ capable of binding about $50 \%$ of the labelled antigen was incubated for $24 \mathrm{~h}$ at room temperature with $0.05 \mathrm{ml}$ of unlabelled standard antigen (Col $1-3$ ) or unknown sample, $0.1 \mathrm{ml}$ (20000 counts/min) of labelled antigen and $0.25 \mathrm{ml}$ of phosphate buffered saline/Tween $0.05 \mathrm{~mol} / 1, \mathrm{pH} 7.5$ buffer. Following the addition of $0.1 \mathrm{ml}$ of anti-rabbit IgG goat serum diluted $1 / 20$ in 1/200 normal rabbit serum and $1 \mathrm{ml}$ polyethylene glycol $6000(15 \mathrm{~g} / \mathrm{l})$, the tubes were further incubated for $30 \mathrm{~min}$. The precipitate was collected by centrifugation at $4000 \mathrm{~g}$ for $30 \mathrm{~min}$ at $4{ }^{\circ} \mathrm{C}$ and the radioactivity measured.

A typical standard curve is shown in figure 1.

The sensitivity of the assay was $1 \mu \mathrm{g} / \mathrm{l}$. The within and between assays coefficients of variation were less than $15 \%$ (for concentrations ranging between 2 and $150 \mu \mathrm{g} / \mathrm{l})$. The upper limit of normal values (mean $\pm 2 \mathrm{SD}$ ) was established as $15 \mu \mathrm{g} / \mathrm{l}$ (Hartmann et al., in preparation).

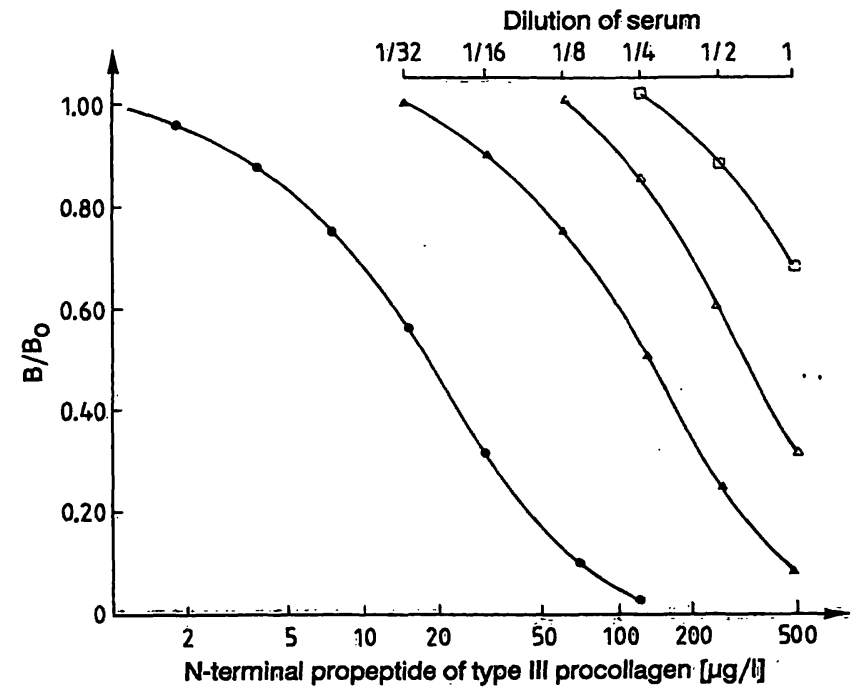

Fig. 1. Typical standard curve for the determination of human aminoterminal propeptide of type III procollagen (๑). Insert: dilution of sera from a healthy subject ( $\square$ ) and 2 patients with schistosomiasis $(\Delta, \Delta)$

$$
\text { : }
$$

Eur. J. Clin. Chem. Clin. Biochem. / Vol. 29, 1991 / No. 11 
To determine the molecular mass of immunoreactive components in serum, we chromatographed $2 \mathrm{ml}$ of normal human serum on a $1.6 \times 130 \mathrm{~cm}$ column of Sephacryl S 500 (Pharmacia, Uppsala, Sweden) equilibrated in phosphate buffered saline containing $0.4 \mathrm{ml}$ of Tween 20 per liter, eluting at a flow rate of $20 \mathrm{ml} / \mathrm{h}$. We collected and assayed $1.5 \mathrm{ml}$ fractions. This assay mainly recognized intact aminoterminal propeptide of type III procollagen and high molecular weight components, and small degradation products such as Col-1 were recognized weakly, if at all (fig. 2).

Data were analysed for statistical significance by the unpaired Mann-Whitney U test. The non-parametric Spearman rank correlation coefficients were calculated (Statgraphics Software, STSC).

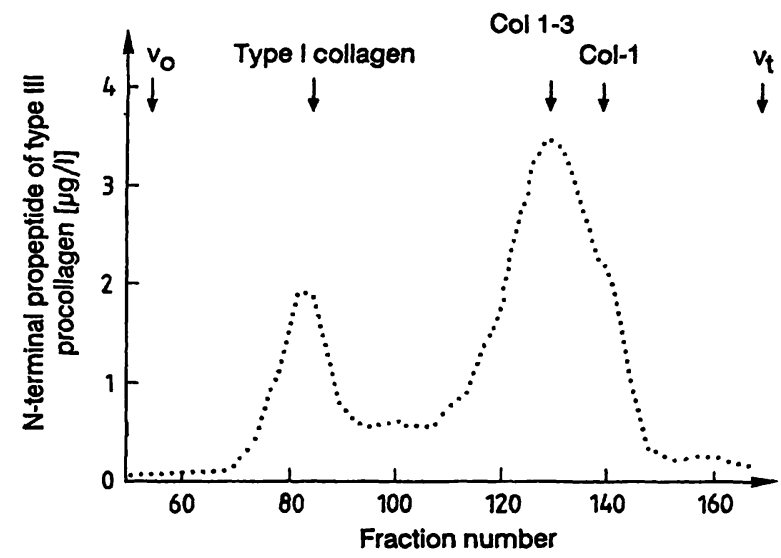

Fig. 2. Distribution of aminoterminal propeptide of type III procollagen antigen in normal human serum after chromatography on a Sephacryl S 500 column. Inhibition activity was measured in $1.5 \mathrm{ml}$ individual fractions of the eluent by direct radioimmunoassay. The column was calibrated with ${ }^{125}$ I-labelled type I collagen, non-labelled Col 1-3 and Col-1. $v_{0}$ and $v_{t}$ denote the void and total volumes of the column.

\section{Results}

Results of the liver function tests in patients and normal controls are summarized in table 2. Serum levels of aminoterminal propeptide of type III procollagen in all patients $(14.2 \pm 6.2 \mu \mathrm{g} / \mathrm{l})($ mean $\pm \mathrm{SD})$ were higher than those in controls $(11.4 \pm 2.0 \mu \mathrm{g} / \mathrm{l})$ $(p=0.05$ ) (tab. 3 and fig. 3). Patients with active liver fibrosis had higher aminoterminal propeptide of type III procollagen values $(16.9 \pm 5.7 \mu \mathrm{g} / \mathrm{l})$ than patients with inactive liver fibrosis $(9.1 \pm 3.5 \mu \mathrm{g} / \mathrm{l})$ $(\mathrm{p}<0.001)$.
Tab. 3. Aminoterminal propeptide of type III procollagen levels in patients with schistosomiasis

\begin{tabular}{lll}
\hline Group & Aminoterminal & Mann-Whitney \\
& propeptide of type test \\
& III procollagen \\
& $\mathrm{x} \pm \mathrm{S} . \mathrm{D} .(\mu \mathrm{g} / \mathrm{l})$ \\
\hline
\end{tabular}

$\left.\begin{array}{lrl}\hline \text { Control } & 11.4 \pm 2.0 \\ \text { Active fibrosis } & 16.9 \pm 5.7 \\ \text { Inactive fibrosis } & 9.1 \pm 3.5 \\ \text { Total schistosomal } & 14.2 \pm 6.2 & \end{array}\right] * * \quad$ NS ${ }^{* * *}$

fibrosis

$$
\begin{array}{rl}
* & p<10^{-4} \\
* * & p<10^{-3} \\
* * * & p=0.05
\end{array}
$$

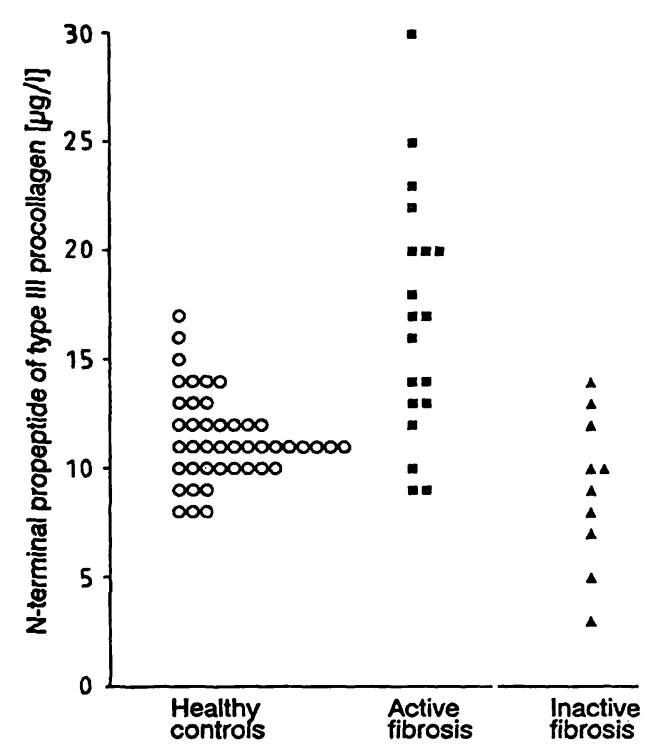

Fig. 3. Serum procollagen III peptide values in patients with schistosomiasis and in normal controls.

No significant correlation was observed between aminoterminal propeptide of type III procollagen and liver function tests (alanine aminotransferase, aspartate aminotransferase), in particular in patients with

\begin{tabular}{|c|c|c|c|}
\hline \multirow[t]{2}{*}{ Liver test } & \multirow{2}{*}{$\begin{array}{l}\text { Group of normal controls } \\
(n=44)\end{array}$} & \multicolumn{2}{|c|}{ Group of patients with pure schistosomal fibrosis } \\
\hline & & active $(n=19)$ & inactive $(n=10)$ \\
\hline $\begin{array}{l}\text { Albumin }(\mathrm{g} / \mathrm{l}) \\
\gamma \text {-Globulins }(\mathrm{g} / \mathrm{l}) \\
\text { Aspartate aminotransferase }(\mathrm{U} / \mathrm{l}) \\
\text { Alanine aminotransferase }(\mathrm{U} / \mathrm{l}) \\
\gamma \text {-Glutamyl transferase }(\mathrm{U} / \mathrm{l}) \\
\text { Alkaline phosphatase }(\mathrm{U} / \mathrm{l}) \\
\text { Bilirubin (mg/l) }\end{array}$ & $\begin{array}{r}41.0 \pm 4.0 \\
14.0 \pm 3.1 \\
12.2 \pm 4.4 \\
8.1 \pm 2.8 \\
16.9 \pm 9.7 \\
32.4 \pm 9.2 \\
11.0 \pm 8.4\end{array}$ & $\begin{array}{l}38.0 \pm 8.0 \\
21.0 \pm 7.0 \\
28.3 \pm 22.0 \\
17.8 \pm 13.4 \\
80.3 \pm 58.7 \\
42.4 \pm 15.3 \\
9.1 \pm 5.0\end{array}$ & $\begin{array}{r}33.1 \pm 0.4 \\
22.8 \pm 7.2 \\
19.8 \pm 11.2 \\
17.8 \pm 13.0 \\
62.9 \pm 50.4 \\
48.2 \pm 3.3 \\
9.6 \pm 3.3\end{array}$ \\
\hline
\end{tabular}
active or inactive schistosomal liver fibrosis.

Tab. 2. Liver function tests of the different groups of patients with hepatosplenic schistosomiasis (mean $\pm S$. D.)

n: number of subjects 


\section{Discussion}

During schistosomiasis a greatly increased total hepatic collagen content has been demonstrated (10). The various types of the deposited collagen have been characterized by immunocytochemistry at different stages of schistosome granulomata $(18,19)$ and thus collagen typing has become important in the evaluation of the dynamics and prognosis of hepatic fibrosis. Until recently, histological examination of biopsies was therefore the only reliable method for determining the extent and progress of fibrosis in the liver.

In liver diseases, the measurement of aminoterminal propeptide of type III procollagen in serum by radioimmunoassay has been proposed as a non-invasive parameter. The antigens recognized in the different aminoterminal propeptide of type III procollagen assays were found to be heterogeneous in human serum, where there are at least 4 immunoreactive forms which differ in their molecular size (13). Aminoterminal propeptide of type III procollagen is the intact trimeric aminoterminal propeptide of collagen III (Col $1-3)$ with a molecular mass of $M_{\mathrm{r}}=45000(14,20)$. Its degradation product, Col-1 $\left(M_{\mathrm{r}}=10000\right)$, is only weakly cross-reactive in the conventional aminoterminal propeptide of type III procollagen RIA (14). There are also larger forms recognized by the antibodies: one may represent type III procollagen or $p$ $N$-III collagen, the other, somewhat larger than the propeptide, may be aggregated aminoterminal propeptide of type III procollagen or a degradation product of type III procollagen. Moreover their proportion may vary in patient serum according to the disease and even during the different phases of a given disease (13). In addition, these circulating antigens do not present the same affinity for the antibody as does purified aminoterminal propeptide of type III procollagen. Thus, the apparent proportions of the different forms in any serum sample can vary according to the antisera and the assay conditions used.

The first radioimmunoassay for aminoterminal propeptide of type III procollagen was described by Rohde (14); the curve slope was less steep than that for the bovine reference peptide, so the following improvements were proposed. In order to quantitate mainly the low molecular forms, Pierard et al. (17) reported a modified radioimmunoassay using as standard the antigen generated by cleavage of bovine aminoterminal propeptide of type III procollagen with bacterial collagenase (Col-1 plus Col-2), while Rohde et al. (21) introduced an assay using pepsincleaved antibody ( $F_{a b}$ fragments), the affinity of the intact propeptide and its degradation product (Col-1) to these $\mathrm{F}_{\mathrm{ab}}$ being nearly identical. In contrast, Risteli et al. (22) recently used a highly purified human antigen, and did not detect the small aminoterminal propeptide of type III procollagen degradation products in serum.

In this study we used the assay of Pierard et al. (17) with some modifications, with Col $1-3$ as a standard. Under the chosen reaction con'ditions (22) (Harmann et al., in preparation), the reactivity of small degradation products was reduced (fig. 2) and the displacement curves obtained with the antigen and serially diluted human sera were parallel (fig. 1).

An increased serum aminoterminal propeptide of type III procollagen might reflect a de novo synthesis of type III procollagen in the liver, since the aminopropeptide is partly liberated during the conversion of procollagen into collagen in stoichiometric amounts, but it may also reflect the degradation of tissue type III collagen still containing the aminoterminal propeptide $(13,15)$.

We found that serum aminoterminal propeptide of type III procollagen was elevated in most of patients with an active stage of schistosomal liver fibrosis and not during an inactive stage. Such an increase may be attributed to an increased collagen synthesis (correlated with higher levels of synthesis enzymes) and/ or also to enhancement of collagenolytic activities in the early stages of schistosomiasis $(8,23)$. The lower serum levels observed in schistosomal patients with inactive liver fibrosis may be related to the absence of (or minimal) fibrogenic activity (synthesis or degradation) and/or to an increased deposition of type I collagen rather than type HI collagen in the liver during this stage. Our findings are in agreement with El-Mohandes et al. (16) and Bolarin et al. (23) for schistosomiasis, and also with studies on other liver diseases $(14,24-27)$, showing that aminoterminal propeptide of type III procollagen is likely to be a marker of disease activity. The present data show no correlation between aminoterminal propeptide of type III procollagen and aspartate aminotransferase or alanine aminotransferase in patients with an inactive or an active stage, in contrast to what has been observed in other situations $(14,24,27)$. However this result is an agreement with El-Mohandes et al. (16) and Roberts et al. data (28): in patients with schistosomiasis, increased aminoterminal propeptide of type III procollagen serum levels were reported, but without any correlation with necrosis. As serum aminoterminal propeptide of type III procollagen is likely to be modified during granuloma resorption due to increased collagenolytic activities, naturally $(8$, 11) or after treatment with praziquantel (29), we have undertaken follow-up studies of individuals to assess

Eut. J. Clin. Chem. Clin. Biochem. / Vol. 29, 1991 / No. 11 
the prognostic value of aminoterminal propeptide of type III procollagen and its usefulness during antischistosomal chemotherapy.

\section{Acknowledgements}

We acknowledge the financial support of the CNRS, France, and the Egyptian Academy of Scientific Research and Technology. H. H. is a recipient of a fellowship from the French Ministery of Foreign Office through a cooperative agreement

\section{References}

1. Warren, K. S. (1980) The relevance of schistosomiasis. N. Engl. J. Med. 303, 203-206.

2. Dunn, M. A. \& Kamel, R. (1981) Hepatic schistosomiasis. Hepatology 1, 653-659.

3. Zwingenberger, K., Feldmeier, H., Nogueira Queiroz, J. A., Vergetti Siqueira, J. G., Farias Auto, H., Alencar, J. E. \& Bienzle, U. (1988) Liver involvement in human schistosomiasis mansoni. Assessment by immunological and biochemical markers. Parasitol. Res. 74, 448 - 455.

4. Popper, H. \& Udenfriend, S. (1970) Hepatic fibrosis. Correlation of biochemical and morphological investigations. Am. J. Med. 49, 707-721.

5. Gressner, A. M. (1991) Liver fibrosis: Perspectives in pathobiochemical research and clinical outlook. Eur. J. Clin. Chem. Clin. Biochem. 29, 293-311.

6. Rojkind, M., Giambrone, M. A. \& Biempica, L. (1979) Collagen types in normal and cirrhotic liver. Gastroenterology 76, 710-715.

7. Biagini, G. \& Ballardini, G. (1989) Liver fibrosis and extracellular matrix. J. Hepatol. 8, 115-124.

8. El Meneza, S., Olds, G. R., Kresina, T. F. \& Mahmoud, A. A. F. (1989) Dynamics of hepatic connective tissue matrix constituents during murine Schistosoma Mansoni infection. Hepatology 9, 50-56.

9. Schuppan, D. (1990) Structure of the extracellular matrix in normal and fibrotic liver: collagens and glycoproteins. Sem. Liver Dis. 10, 1-10.

10. Dunn, M. A., Kamel, R., Kamel, I. A., Biempica, L., ElKholy, A., Hait, P. K., Rojkind, M., Warren, K. S. \& Mahmoud, A. A. F. (1979) Liver collagen synthesis in schistosomiasis mansoni. Gastroenterology 76, 978-982.

11. Junqueira, L. C. U., Montes, G. S., Toledo, O. M. S. \& Joazeiro, P. P. (1986) Morphological, histochemical and biochemical observations on the connective tissue matrix of in situ and isolated hepatic granulomas in experimental murine schistosomiasis. Ann. Trop. Med. Parasitol. 80, $27-41$.

12. Gressner, A. M. (1987) Measurement of connective tissue parameters in serum for diagnosis and follow-up of liver fibrosis. Ann. Clin. Biochem. 24, 283-292.

13. Risteli, L. \& Risteli, J. (1990) Noninvasive methods for detection of organ fibrosis. In: Focus on connective tissue in health and disease (Rojkind, M., ed.) vol. 1, pp. 61-98, CRC Press, New York.

14. Rohde, H., Vargas, L., Hahn, E., Kalbfleisch, H., Bruguera, M. \& Timpl, R. (1979) Radioimmunoassay for type III procollagen peptide and its application to human liver disease. Eur. J. Clin. Invest. 9, 451-459.

15. Rojkind, M. (1984) The blue glass and the predictive value of serum amino-terminal propeptide of type III procollagen. as a marker of liver fibrosis. Hepatology 4, 977-978.

16. El-Mohandes, M., Hassanein, H., El-Badrawy, N., Voss, B. \& Gerlach; U. (1987) Serum concentration of N-terminal procollagen peptide of collagen type III in schistosomal liver fibrosis. Exp. Mol. Pathol. 46, 383-390.

17. Pierard, D., Nusgens, B. V. \& Lapiere, C. M. (1984) Radioimmunoassay for the amino-terminal sequences of type between the Theodor Bilharz Research Institute and the Institut Pastcur de Lyon.

We are grateful to Dr. P. Chossegros (INSERM Unit 271), $\mathrm{Pr}$ Dr. A. El-Kalouby, Pr. Dr. Z. Shaker (Theodor Bilharz Research Institute) and Dr. J. A. Grimaud, Dr. M. Chevallier (Institute Pasteur) for their helpful encouragement. We thank $\operatorname{Dr} A$. Cotisson and Mrs $H$. Abo Taleb who performed the statistical analysis, Pr. Dr. H. Abd-El-Rahman for the liver function tests, and Dr. S. Bahgat, Dr. S. Saied (Theodor Bilharz Research Institute), F. Billiemaz, S. Castebert, F. Limandas and F. Roux (Institut Pasteur) for their cooperation.

III procollagen in human body fluids measuring fragmented precursor sequences. Anal. Biochem. 141, 127-136.

18. Al Adnani, M. S. (1985) Concomitant immunohistochemical localization of fibronectin and collagen in schistosome granulomata. J. Pathol. 147, 77-85.

19. Biempica, L., Dunn, M. A., Kamel, I. A., Kamel, R., Hait, P. K., Fleischner, C., Biempica, S. L., Wu, C. H. \& Rojkind, M. (1983) Liver collagen-type characterization in human schistosomiasis. A histological, ultrastructural, and immunocytochemical correlation. Am. J. Trop. Med. Hyg. 32, $316-325$.

20. Niemelä, O., Risteli, L., Parkkinen, J. \& Risteli, J. (1985) Purification and characterization of the N-terminal propeptide of human type III procollagen. Biochem. J. 232, $145-150$.

21. Rohde, H., Langer, I., Krieg, T. \& Timpl, R. (1983) Serum and urine analysis of the amino-terminal procollagen peptide type III by radioimmunoassay with antibody Fab fragments. Coll. Relat. Res. 3, 371-379.

22. Risteli, J., Niemi, S., Trivedi, P., Mäentausta, O., Mowat, A. P. \& Risteli, L. (1988) Rapid equilibrium radioimmunoassay for the amino-terminal propeptide of human type III procollagen. Clin. Chem. 34, 715-718.

23. Bolarin, D. M., Savolainen, E. R. \& Kivirikko, K. I. (1984) Three serum markers of collagen biosynthesis in Nigerians with cirrhosis and various infectious diseases. Eur. J. Clin. Invest. 14, 90-95.

24. Frei, A., Zimmermann, A. \& Weigand, K. (1984) The Nterminal propeptide of collagen type III in serum reflects activity and degree of fibrosis in patients with chronic liver disease. Hepatology 4, 830-834.

25. Savolainen, E. R., Goldberg, B., Leo, M. A., Velez, M. \& Lieber, C. S. (1984) Diagnostic value of serum procollagen peptide measurements in alcoholic liver disease. Alcohol. Clin. Exp. Res. 8, 384-389.

26. Surrenti, C., Casini, A., Milani, S., Ambu, S., Ceccatelli, P. \& D'Agata, A. (1987) Is determination of serum Nterminal procollagen type III peptide (sPIIIP) a marker of hepatic fibrosis? Dig. Dis. Sci. 32, 705-709.

27. Trinchet, J. C., Hartmann, D. J., Pateron, D., Laarif, M., Callard, P., Ville, G. \& Beaugrand, M. (1991) Serum type I collagen and $\mathrm{N}$-terminal peptide of type III procollagen in chronic hepatitis. Relationship to liver histology and conventional liver tests. J. Hepatol. 12, 139-144.

28. Roberts, F. D., Halliday, J. W., Cooksley, W. G. E., Sandford, N., Karawi, M., Shahed, M., Mohamed, A. \& Powell, L. W. (1986) Serum procollagen-III-peptide in chronic hepatitis and schistosomiasis. J. Gastroenterol. Hepatol. I, $333-338$.

29. Emonard, H. \& Grimaud, J. A. (1989) Active and latent collagenase activity during reversal of hepatic fibrosis in murine schistosomiasis. Hepatology 10, 77-83.

V. Fayol

Centre de Radioanalyse

Institut Pasteur de Lyon

$13-15$, rue Domer

F-69366 Lyon Cedex 07 
